\title{
Holospinal epidural abscess of the spinal axis: two illustrative cases with review of treatment strategies and surgical techniques
}

\author{
Gabriel A. Smith, M.D., ${ }^{1,2}$ Arshneel S. Kochar, B.A., ${ }^{2}$ Sunil Manjila, M.D., ${ }^{1,2}$ \\ Kaine Onwuzulike, M.D., Ph.D., ${ }^{1,2}$ Robert T. Geertman, M.D., Ph.D., ${ }^{2,3}$ \\ James S. Anderson, M.D., ${ }^{2,3}$ And Michael P. Steinmetz, M.D., ${ }^{2,3}$ \\ ${ }^{1}$ Department of Neurological Surgery, University Hospitals, Case Medical Center; ${ }^{2}$ Case Western Reserve \\ University School of Medicine; and ${ }^{3}$ Department of Neurological Surgery, MetroHealth Medical Center, \\ Cleveland, Ohio
}

\begin{abstract}
Despite the increasing prevalence of spinal infections, the subcategory of holospinal epidural abscesses (HEAs) is extremely infrequent and requires unique management. Panspinal imaging (preferably MRI), modern aggressive antibiotic therapy, and prompt surgical intervention remain the standard of care for all spinal axis infections including HEAs; however, the surgical decision making on timing and extent of the procedure still remain ill defined for HEAs. Decompression including skip laminectomies or laminoplasties is described, with varied clinical outcomes. In this review the authors present the illustrative cases of 2 patients with HEAs who were treated using skip laminectomies and epidural catheter irrigation techniques. The discussion highlights different management strategies including the role of conservative (nonsurgical) management in these lesions, especially with an already identified pathogen and the absence of mass effect on MRI or significant neurological defects.

Among fewer than 25 case reports of HEA published in the past 25 years, the most important aspect in deciding a role for surgery is the neurological examination. Nearly $20 \%$ were treated successfully with medical therapy alone if neurologically intact. None of the reported cases had an associated cranial infection with HEA, because the dural adhesion around the foramen magnum prevented rostral spread of infection. Traditionally a posterior approach to the epidural space with irrigation is performed, unless an extensive focal ventral collection is causing cord compression. Surgical intervention for HEA should be an adjuvant treatment strategy for all acutely deteriorating patients, whereas aspiration of other infected sites like a psoas abscess can determine an infective pathogen, and appropriate antibiotic treatment may avoid surgical intervention in the neurologically intact patient.
\end{abstract}

(http://thejns.org/doi/abs/10.3171/2014.5.FOCUS14136)

\section{KeY WoRdS • epidural abscess holospinal epidural abscess}

spinal infection skip laminectomy -
S PINAL axis infections are increasing in prevalence secondary to increasing numbers of spinal surgeries around the world..$^{2,24,41}$ Spinal infections are a serious health care dilemma occurring in patients with immunodeficiencies, ongoing known infections, and intravenous drug abuse. ${ }^{23,24}$ Epidural abscesses are especially highrisk infections because neurological deterioration can occur rapidly. Nearly $30 \%$ of spinal epidural abscesses do not have a specific source; however, studies estimate that nearly half are from hematogenous seeding, whereas $10 \%-20 \%$ originate from osteomyelitis, hematoma, or soft-tissue infection, and $20 \%$ are iatrogenic. ${ }^{25,27,37,38,45,55}$ Modern aggressive antibiotic therapy and supportive care have improved outcomes in certain patient populations who have an epidural spinal infection. 2,27,37,40

Holospinal epidural abscesses (HEAs) are exceedingly rare, with very few documented cases in the literature. ${ }^{30,47}$ Neurological decline is an absolute indication for

Abbreviations used in this paper: HEA = holospinal epidural abscess; MRSA = methicillin-resistant Staphylococcus aureus. surgery, ${ }^{13}$ and many authors advocate aggressive surgical intervention above the conus even in the face of normal findings on neurological examination. Surgical options for spinal epidural abscesses traditionally include decompression and evacuation of the abscess, additional debridement of osteomyelitic bone and involved disc, and careful laminar reconstruction. ${ }^{31}$ However, very few studies have elucidated a standard surgical management strategy for HEAs. In this institutional case series we attempt to highlight the clinical presentation of HEA, the options available for identifying the infective etiology, and strategies for abscess evacuation and stabilization of the spine.

Case 1

\section{Illustrative Cases}

History and Examination. A 5-year-old boy with no known medical history presented with a single day of progressively worsening abdominal, hip, and leg pain. His parents noted progressive weakness of his legs with ascending sensory loss. On arrival in the emergency room, 
his neurological examination was notable for $0 / 5$ strength, decreased sensation and hyporeflexia in bilateral lower extremities, 4/5 strength in bilateral upper extremities, sensory level at T-2, and loss of rectal tone. Temperature was $39.2^{\circ} \mathrm{C}$, and he had a profound leukocytosis of $47.9 \times$ $10^{3} / \mu \mathrm{l}$ with $93 \%$ bands. His C-reactive protein level was 22.1 (normal $<1.0 \mathrm{mg} / \mathrm{dl}$ ). An MRI study of the spine revealed an abnormal 5-mm-thick epidural fluid collection posterolaterally from $\mathrm{C}-1$ to the bottom of the sacral canal that was highly suggestive of HEA with cord compression (Fig. 1).

Operation and Postoperative Course. Given these findings and his acute paraplegia, the patient was taken to the operating room and underwent emergency laminectomies at C6-7, T7-8, and L-1 through 3 separate incisions. An epidural catheter was used to irrigate any liquefied pus above and below each laminectomy site. Drains were placed both in the epidural space and above the fascia, and the incisions were closed in a typical fashion. Postoperatively he was placed on broad-spectrum antibiotics. His cultures grew methicillin-resistant Staphylococcus aureus (MRSA), his antibiotics were then narrowed to linezolid, and he completed a 12-week course of treatment. Additional workup revealed endocarditis, hip effusions, and subperiosteal tibial abscesses. He was discharged 3.5 weeks postoperatively to a rehabilitation facility, where he was noted to have improved sphincter and bladder function. His neurological examination performed at the time showed unchanged motor strength but improved tone present in his ankle and hips, with a sensory level at T-3. The 1- and 3-month follow-up MRI studies showed complete resolution of the epidural abscess; however, his examination results had not improved with rehabilitation.

Case 2

History and Examination. A 51-year-old man with no known medical history presented with several days of worsening back pain, but no lower-extremity weakness. On presentation to the emergency department he was afe- brile at $36.1^{\circ} \mathrm{C}$, with a white blood cell count of $24 \times 10^{3} /$ $\mu \mathrm{l}$, and a C-reactive protein level of $42.3 \mathrm{mg} / \mathrm{dl}$ (normal $<1.0$ ). Neurological examination results were notable for profound diaphoresis and diffuse tenderness to palpation over his back, but he had full strength. An MRI study revealed extensive epidural abscess circumferentially throughout the entire spinal canal, but it was worst at the thoracolumbar junction (Fig. 2).

Operation and Postoperative Course. The patient was taken to the operating room for an emergency evacuation. Laminectomy of L-3 was done, and ample white purulent material was encountered. Samples were obtained and sent for Gram stain and culture, and a catheter was used to wash out the epidural space rostral and caudal to the laminectomy. Six days later, his neurological examination deteriorated and he was quadriparetic. Emergency MRI studies showed interval increased size of a ventral collection at the craniovertebral junction posterior to the clivus, with cord compression. The patient was taken to the operating room for an emergency $\mathrm{C} 1-2$ laminectomy. No epidural catheters were used in this approach. He was discharged to rehabilitation 3 weeks after admission with greatly improved upper-extremity strength $(5 / 5)$ bilaterally, but no change in the results of his lower-extremity examination, which remained $1 / 5$ bilaterally. His cultures were positive for MRSA, and he completed a 3-month course of linezolid and rifampin. Fourteen weeks postoperatively, he gained some strength in dorsiflexion and plantar flexion of the left foot, with Grade 3/5 and 4/5 strength, respectively. Initial 2-month postoperative MRI studies showed total resolution of the cervical epidural collection and decreased swelling of the cervical spine. By 11 months postoperatively, he was ambulating with assistance and with minimal residual weakness.

\section{Discussion}

As detailed by Chen et al., ${ }^{13}$ spinal epidural abscesses were first reported by Morgagni in 1761 and represent 1 of
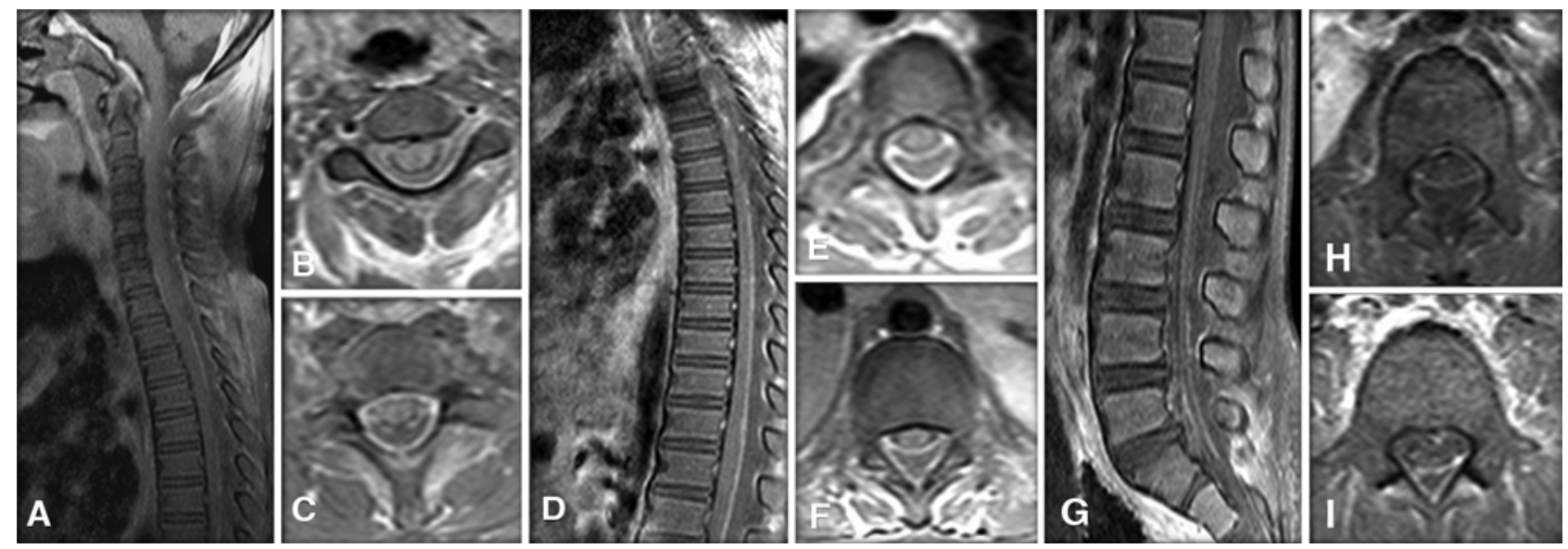

FIG. 1. Case 1. Preoperative T1-weighted MRI sequences obtained with Gd enhancement of an HEA in a 5-year-old boy. Midsagittal views showing extensive HEA (A, D, and G). Axial imaging at C-3 and C-7 revealing a large ventral collection (B and C). Axial imaging at T-3 (E) and T-10 (F) showing extensive dorsal collection with cord compression at T-3. Axial imaging at T-12 (H) and L-3 (I) showing a large dorsal component. 

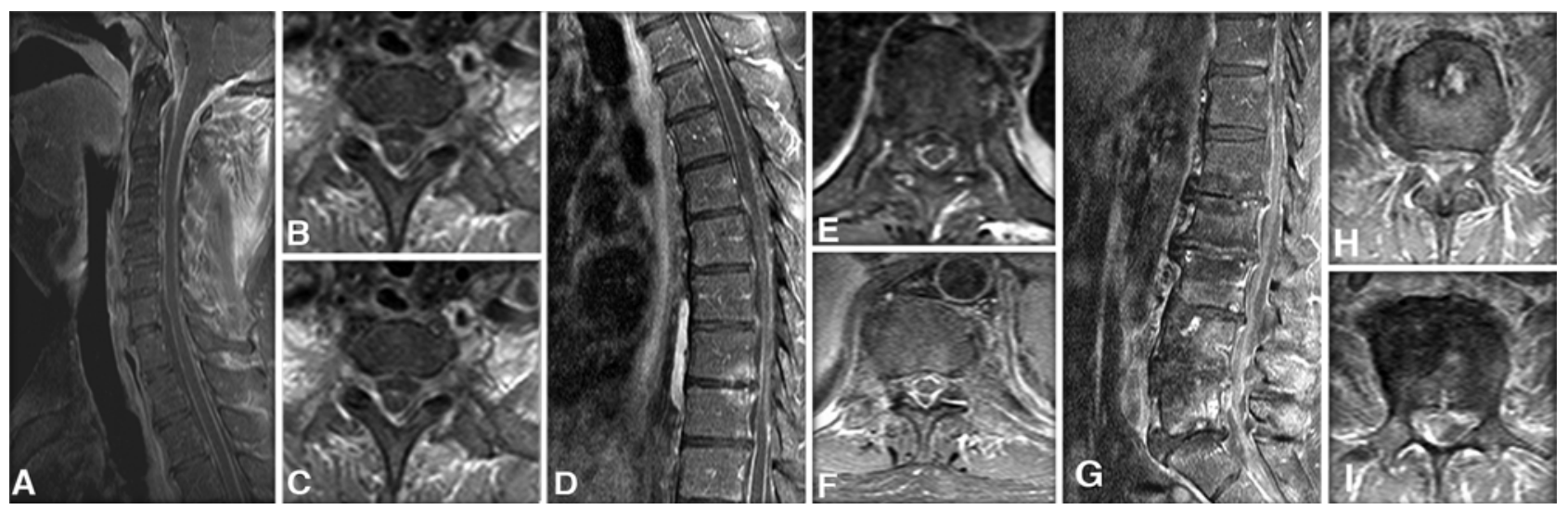

FIG. 2. Case 2. Preoperative T1-weighted MRI sequences with Gd enhancement of an HEA in a 51-year-old man. Midsagittal view showing circumferential extension (A). Axial imaging at C-5 (B) and C-7 (C) revealing a large ventral collection. Thoracic view (D) showing extension circumferentially down to the lower thoracic levels with axial imaging at T-5 (E) and T-10 (F), with extensive ventral and dorsal components. Lumbar imaging $(G)$ also revealing panspinal extension of the epidural abscess surrounding the thecal sac. Axial imaging at T-12 $(\mathrm{H})$ and L-1 (I) revealing a focus of dorsal abscess with compression of the conus.

10,000 hospital admissions annually in the US. ${ }^{6,41}$ To our knowledge, fewer than 25 reported cases of HEA exist in the literature. ${ }^{16,21,22,30,32-34,36,47-51,53,54}$ Known risk factors for HEA in adults include diabetes mellitus, intravenous drug abuse, immunosuppression (Crohn's disease, malignancy, steroid use, cirrhosis, and hepatitis), and pregnancy. ${ }^{16,21,22,30,32-34,36,47-51,53,54}$ Holospinal epidural abscesses classically present with severe spinal pain, myelopathic or radicular deficits, profound leukocytosis, and elevations in inflammatory markers. ${ }^{30,48}$ Blood cultures are essential in early pathogen identification and are positive in up to $60 \%$ of cases. ${ }^{38,45}$ Extensive psoas abscesses and contiguous soft-tissue infections are also well described. ${ }^{20,47,57}$

In most cases HEAs are associated with $S$. aureus infections, with no predisposition for age or an immunocompromised state. The natural history of spinal epidural abscesses suggests that they spread contiguously or hematogenously, and we hypothesize that HEAs develop no differently. ${ }^{16,21,22,30,32-34,36,47-51,53,54}$ Diagnosis is typically made by MRI, and these cases highlight the critical role of imaging of the entire neural axis because paraspinal, psoas, and even adjacent abdominal infections can occur., $, 17,29,39,48$ Risk factors for failure of medical therapy include deteriorating neurological examination, persistent bacteremia, age older than 65 years, and MRSA as the identified pathogen..$^{27,37}$ Use of MRI is essential for delineating phlegmon from liquid pus prior to determining a surgical approach. Homogeneous enhancement on T1weighted sequences obtained with $\mathrm{Gd}$, and hyperintensity throughout the lesion on T2-weighted sequences is more consistent with phlegmon, whereas bright rim enhancement with a hypointense core on T1-weighted images is suggestive of liquid pus. ${ }^{2,17,29,39,48}$

Emergency surgical intervention is often required, especially in the neurologically deteriorating patient. Ongoing debate exists regarding the pathophysiological mechanisms of neurological deterioration in spinal epidural abscesses. Rabbit model studies with direct inoculation are suggestive of focal cord compression as a causative factor. ${ }^{18,19,46}$ However, hematogenous spread is also a well- known etiology. In these cases, arteritis, venous thrombosis, or septic thrombophlebitis leading to spinal cord infarction have been found postmortem, representing the most likely causative mechanism for neurological deterioration. $3,5,43$ The pathophysiology of spinal cord injury in the setting of infection is an area of active research; however, a monkey model elucidated that high cervical cord compression from tumors leads to venous stasis and hypoxic changes in the spinal cord. ${ }^{52}$ These data prove that arterial and venous compromise from both compression and direct thrombophlebitis contribute to spinal cord injury in the setting of epidural abscesses. Even in neurologically intact patients with abscess above the conus, serious acute to subacute complications can occur from direct compression or these vascular changes. . $^{13,25,26}$

The mainstay of treatment for any neuraxis infection remains broad-spectrum antibiotics. In bacterial meningitis, the consequences of inflammation and arteritis can cause significant morbidity, including profound hearing loss. The literature does support using steroids to quell this inflammation and to prevent significant morbidity. ${ }^{1,12,35}$ In the deteriorating patient with HEA, steroids remain controversial, and further research is necessary to elucidate their efficacy; however the authors believe that the potential benefit outweighs the risks in the acutely deteriorating patient. Blood pressure augmentation is also an area of debate, and has not been studied thoroughly in patients with spinal epidural abscess specifically. However, in neurologically deteriorating patients with trauma it is well known that hypotension is a significant predictor of morbidity and mortality. We would argue that this literature can also be applied to the management of neurologically deteriorating patients with spinal axis infections, and recommend maintaining normotensive blood pressures to prevent cord ischemia.

The goals of surgery are always to decompress the neural elements, evacuate infection, identify the pathogen, and stabilize the spine (if needed) with minimal instrumentation. These goals can be met easily when treating focal epidural abscesses; however, when a large 
number of vertebral levels are involved, potential destabilization can result from the decompression. The surgical strategy in Case 1 was evacuation of as much liquid pus as possible through equidistant laminotomies and adjuvant catheter irrigation in the cervical, thoracic, and lumbar spine. In Case 2 a different strategy was implemented. Lower-extremity weakness was present and focal compression was seen at the level of the conus. Direct decompression with irrigation rostrally and caudally was performed at the thoracolumbar junction, but unfortunately neurological deterioration and repeat imaging revealed focal compression in the axial cervical spine that required decompression.

In a review of 19 HEA cases reported in the literature (Table 1), the age at presentation is variable, ranging from infant to elderly patients. Neurological examination at the time of presentation is critical to the diagnosis and treatment strategies that prior authors have implemented. In total, 4 of the 19 cases were treated without surgical intervention and the patients made full recoveries. Nonsurgical therapy, especially above the conus, has been previously condemned by some authors, and yet these cases suggest a role for nonsurgical therapy alone. ${ }^{15,38}$ In the setting of HEA, nonsurgical therapy must be recommended with extreme caution because the majority of cases in the literature (15 of 19) presented with neurological deterioration. Unfortunately in 1 case, cardiopulmonary arrest occurred prior to surgical intervention, highlighting the inherent severity of HEAs. Soft-tissue infections including psoas or paraspinal abscesses were present in 7 of 19 cases, and were associated with anteriorly located components. Psoas abscesses were notably all associated with $S$. aureus if in conjunction with HEAs. ${ }^{20}$ Endocarditis was documented in only one of the cases reported. Moreover, only 2 cases were associated with intravenous drug abuse. ${ }^{56}$ Crohn's disease, uncontrolled diabetes mellitus, hepatitis, and rheumatoid arthritis were present in 7 of 19 cases.

The vast majority of cases were treated with laminotomies without instrumentation, and the use of epidural catheter irrigation was well described in 10 of 14 operative cases. Our theory is that indirect catheter irrigation diminished the burden of infection, prevented further inflammation to the epidural vasculature, and decompressed the thecal sac effectively in all cases documented. In all cases reviewed, surgeons were careful to avoid surgical decompression of the cervicothoracic, thoracolumbar, or lumbosacral junction to prevent destabilization. ${ }^{2,10,14,27,37}$ Moreover, catheter irrigation and aspiration of a panspinal collection appears to be safe and allows surgeons to avoid these junctions to improve evacuation. The volume of pus necessary to consider catheter irrigation remains unclear, and further research is needed on this topic.

A laminectomy may be adequate for a ventral focus of liquid pus, but this will not adequately address a ventrally situated area of compression from phlegmon, debris, or a kyphotic deformity. In the cases reported in the literature, treatment was successful from a posterior approach in all except one, which required an aggressive transoral odontoidectomy for ventral spinal cord com- pression..$^{30}$ As seen in the aforementioned case reported by Lau et al., a large compressive ventral phlegmon component poses a much more difficult problem (see also Baaj et al. ${ }^{4}$ ). Direct decompression in the subaxial cervical spine with discectomy(s) or a corpectomy(s) with evacuation of the ventral abscess under direct visualization should be considered, especially in the setting of focal vertebral osteomyelitis. The use of interbody arthrodesis and instrumentation is effective and safe even in the face of active infection, and should be used for stabilization; however, this is rarely needed in HEA evacuations. ${ }^{2,11,28,44}$ Above the foramen magnum, infection was only present in ventral collections because dural leaflets are known to prevent intracranial spread. ${ }^{42}$ Below the cervical spine, extended approaches such as a costotransversectomy with a transpedicular approach can be used to achieve ventral access in the thoracic spine if inherent spinal destabilization is also present. The surgeon can also consider using a lateral extracavitary or thoracotomy in these instances for decompression when anterior stabilization is required. However, we believe that these approaches are not necessary in the setting of HEA unless a focal ventral compressive lesion is present with no identified pathogen. In all of the reviewed cases, a posterior approach was sufficient for HEA evacuation with an epidural catheter irrigation technique, because HEAs are predominantly liquid pus.

Khanna et al. reported 3 factors that are independently associated with poor outcome in spinal epidural abscesses; patient age, degree of thecal sac compression, and duration of symptoms. ${ }^{26}$ Moreover, a declining examination in the absence of paralysis for less than 36 hours has been associated with better survival and return of function. ${ }^{29,33}$ In the high-risk surgical patient or in one with irreversible fixed paralysis, surgical decision making remains even more controversial. A CT-directed needle aspiration for pathogen diagnosis and medical therapy has been traditionally used in this patient population; however, this treatment strategy has not been proven or used for HEA cases. ${ }^{2,9,14}$ Recovery appears variable specifically in the setting of HEA; however, neurological improvement is documented up to 13 months after presentation in some cases in the literature.

\section{Conclusions}

Patients suspected of having a spinal epidural abscess or HEA require emergency evaluation. Most patients present with neck or back pain, myelopathy, or profound neurological deficits in the setting of systemic signs of infection. Emergency MRI studies of the spinal axis, blood cultures, and a surgical evaluation should be performed. If an HEA is found on imaging, surgical approaches must be considered based on neurological examination results and risk factors for failure of medical therapy. ${ }^{27,37} \mathrm{In}$ the setting of a neurologically intact patient or one improving on broad-spectrum antibiotics with a known pathogen, surgical intervention may not be required (as seen in 4 of 19 cases presented); however, this treatment strategy must be followed with caution because neurological deterioration can be life-threatening in the setting of HEA. We must caution that radiographic signs of a compressive 
Holospinal epidural abscess of the spinal axis

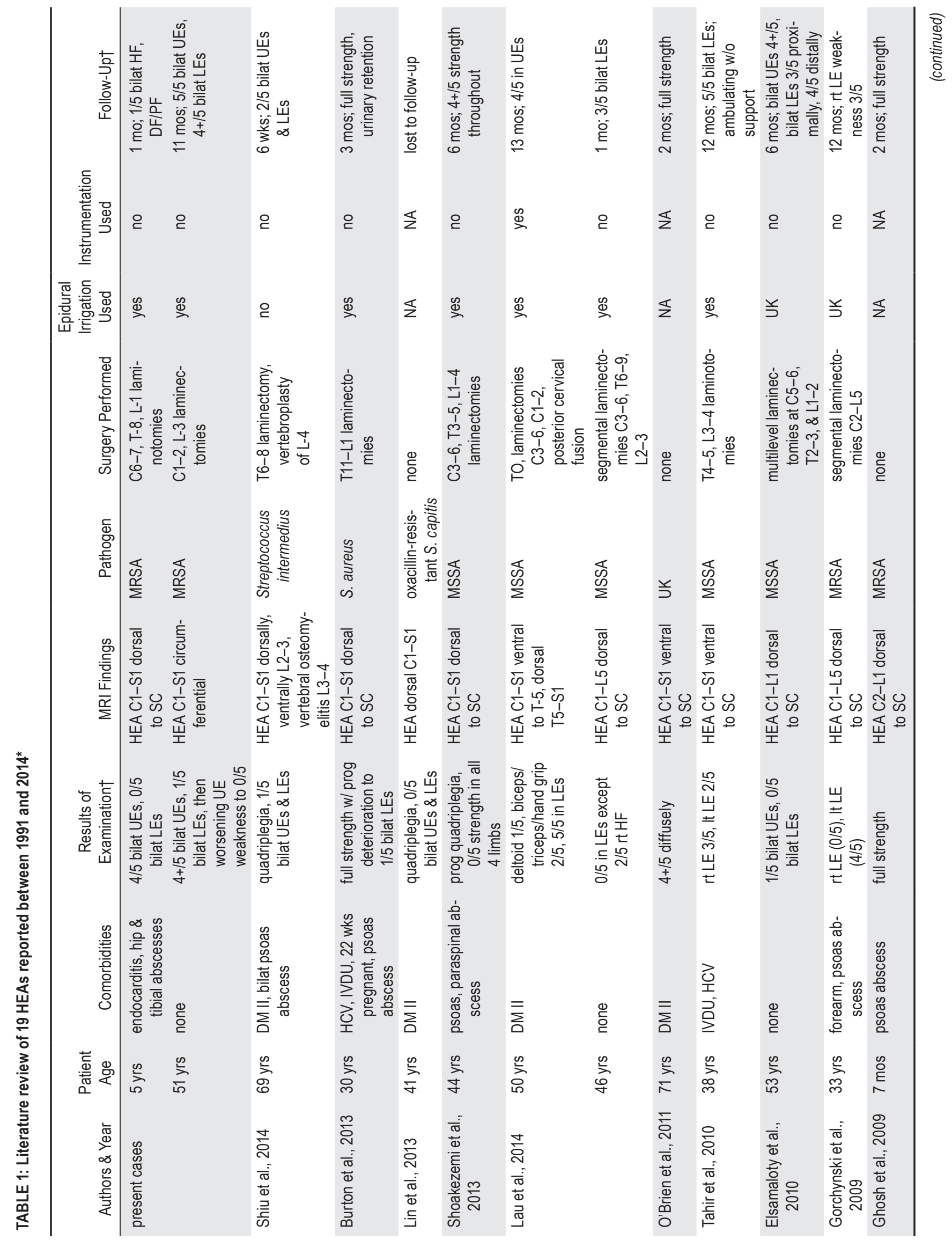


G. A. Smith et al.

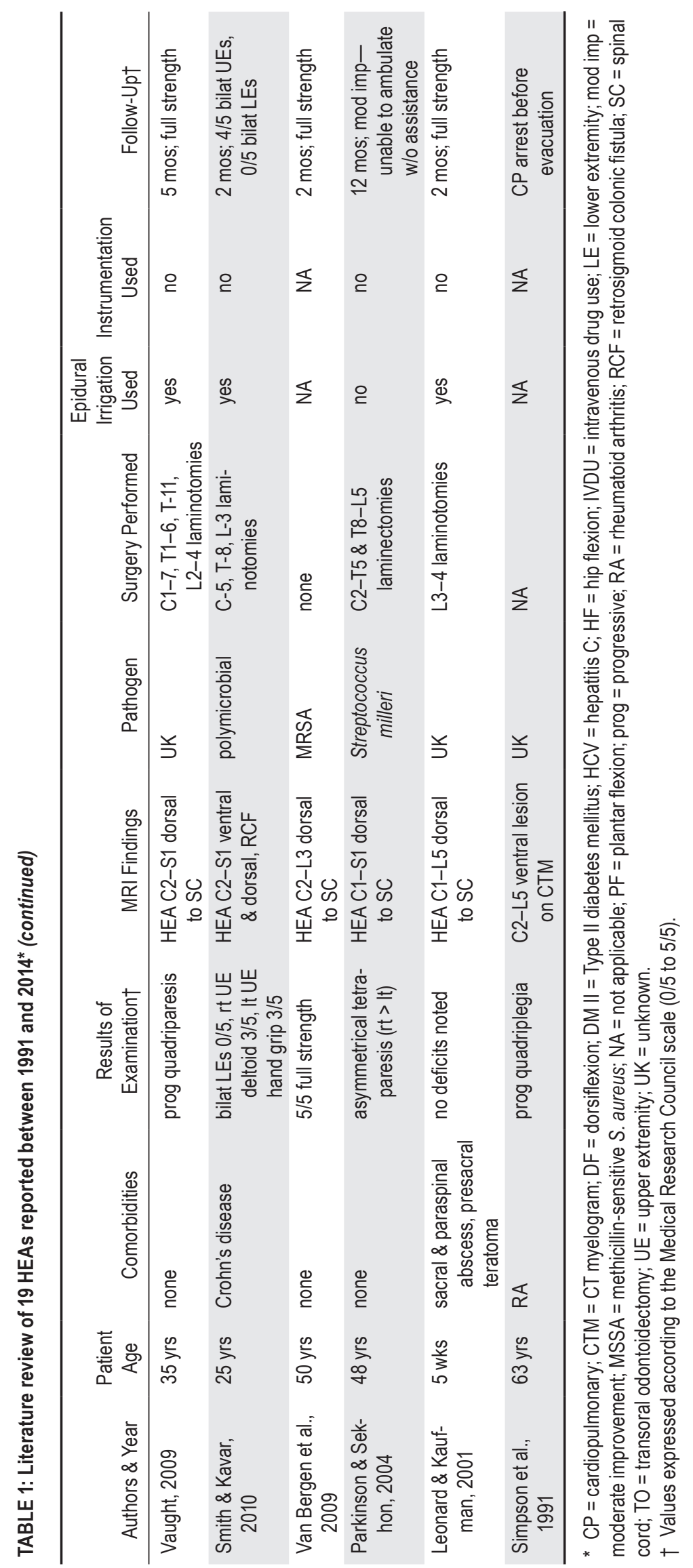


lesion or signs of inflammation such as spinal cord signal changes or edema on MRI studies are red flags, and early surgical evacuation should be considered regardless of neurological status. A surgical approach with posterior laminectomies and catheter irrigation of the epidural space is efficacious and safe in the treatment of liquid pus, which predominates in HEAs, but this approach may not be sufficient if a large ventral component is found above the conus or if phlegmon is present on imaging. We must emphasize that the most important aspect of treatment of HEA remains immediate initiation of broad-spectrum intravenous antibiotics and aggressive medical care. Early surgical intervention for HEA should be an adjuvant treatment strategy for all acutely deteriorating patients.

\section{Disclosure}

Dr. Steinmetz is a consultant for Stryker Spine, Biomet Spine, and DePuy Synthes.

Author contributions to the study and manuscript preparation include the following. Conception and design: all authors. Acquisition of data: all authors. Analysis and interpretation of data: all authors. Drafting the article: Smith, Kochar, Manjila, Onwuzulike, Anderson, Steinmetz. Critically revising the article: Smith, Manjila. Administrative/technical/material support: Smith. Study supervision: Smith.

\section{References}

1. Abraham R: Steroids in neuroinfection. Arq Neuropsiquiatr 71 (9B):717-721, 2013

2. Adogwa O, Karikari IO, Carr KR, Krucoff M, Ajay D, Fatemi $\mathrm{P}$, et al: Spontaneous spinal epidural abscess in patients 50 years of age and older: a 15-year institutional perspective and review of the literature. Clinical article. J Neurosurg Spine 20:344-349, 2014

3. Akalan N, Ozgen T: Infection as a cause of spinal cord compression: a review of 36 spinal epidural abscess cases. Acta Neurochir (Wien) 142:17-23, 2000

4. Baaj AA, Alikhani P, Sack J, Vale FL, Greenberg MS: Drainage of a ventral epidural atlantoaxial abscess via the transoral approach. J Clin Neurosci 19:1044-1045, 2012

5. Baker AS, Ojemann RG, Swartz MN, Richardson EP Jr: Spinal epidural abscess. N Engl J Med 293:463-468, 1975

6. Banco SP, Vaccaro AR, Blam O, Eck JC, Cotler JM, Hilibrand AS, et al: Spine infections: variations in incidence during the academic year. Spine (Phila Pa 1976) 27:962-965, 2002

7. Bullock MR, Povlishock JT: Guidelines for the management of severe traumatic brain injury. Editor's commentary. J Neurotrauma 24 Suppl 1:vii-viii, 2007 (Erratum in J Neurotrauma 25:276-278, 2008)

8. Burton KR, Wang X, Dhanoa D: Holocord spinal epidural abscess in a pregnant patient presenting as premature labour: a rare presentation of an unusual diagnosis. CJEM 15:1-5, 2013

9. Butler JS, Shelly MJ, Timlin M, Powderly WG, O'Byrne JM: Nontuberculous pyogenic spinal infection in adults: a 12-year experience from a tertiary referral center. Spine (Phila Pa 1976) 31:2695-2700, 2006

10. Carpenter W, Afshar N, Mihara K: Spinal epidural abscess with discitis and vertebral osteomyelitis. J Gen Intern Med 27:1560, 2012

11. Carragee EJ: Instrumentation of the infected and unstable spine: a review of 17 cases from the thoracic and lumbar spine with pyogenic infections. J Spinal Disord 10:317-324, 1997

12. Chan ED: Corticosteroids for bacterial meningitis. N Engl J Med 358:1399-1401, 2008 (Letter)
13. Chen WC, Wang JL, Wang JT, Chen YC, Chang SC: Spinal epidural abscess due to Staphylococcus aureus: clinical manifestations and outcomes. J Microbiol Immunol Infect 41: 215-221, 2008

14. Connor DE Jr, Chittiboina P, Caldito G, Nanda A: Comparison of operative and nonoperative management of spinal epidural abscess: a retrospective review of clinical and laboratory predictors of neurological outcome. Clinical article. J Neurosurg Spine 19:119-127, 2013

15. Curry WT Jr, Hoh BL, Amin-Hanjani S, Eskandar EN: Spinal epidural abscess: clinical presentation, management, and outcome. Surg Neurol 63:364-371, 2005

16. Elsamaloty H, Elzawawi M, Abduljabar A: A rare case of extensive spinal epidural abscess in a diabetic patient. Spine (Phila Pa 1976) 35:E53-E56, 2010

17. Euba G, Narváez JA, Nolla JM, Murillo O, Narváez J, GómezVaquero $\mathrm{C}$, et al: Long-term clinical and radiological magnetic resonance imaging outcome of abscess-associated spontaneous pyogenic vertebral osteomyelitis under conservative management. Semin Arthritis Rheum 38:28-40, 2008

18. Feldenzer JA, McKeever PE, Schaberg DR, Campbell JA, Hoff JT: Experimental spinal epidural abscess: a pathophysiological model in the rabbit. Neurosurgery 20:859-867, 1987

19. Feldenzer JA, McKeever PE, Schaberg DR, Campbell JA, Hoff JT: The pathogenesis of spinal epidural abscess: microangiographic studies in an experimental model. J Neurosurg 69:110-114, 1988

20. Flavin NE, Gomez M: Fever, pain, and a limp: a case of a psoas and spinal epidural abscess caused by methicillin-resistant Staphylococcus aureus in a diabetic patient. J Natl Med Assoc 101:84-86, 2009

21. Ghosh PS, Loddenkemper T, Blanco MB, Marks M, Sabella C, Ghosh D: Holocord spinal epidural abscess. J Child Neurol 24:768-771, 2009

22. Gorchynski J, Hwang J, McLaughlin T: A methicillin-resistant Staphylococcus aureus-positive holospinal epidural abscess. Am J Emerg Med 27:514.e7-514.e9, 2009

23. Hlavin ML, Kaminski HJ, Ross JS, Ganz E: Spinal epidural abscess: a ten-year perspective. Neurosurgery 27:177-184, 1990

24. Jensen AG, Espersen F, Skinhøj P, Rosdahl VT, FrimodtMøller N: Increasing frequency of vertebral osteomyelitis following Staphylococcus aureus bacteraemia in Denmark 19801990. J Infect 34:113-118, 1997

25. Karikari IO, Powers CJ, Reynolds RM, Mehta AI, Isaacs RE: Management of a spontaneous spinal epidural abscess: a single-center 10-year experience. Neurosurgery 65:919-924, 2009

26. Khanna RK, Malik GM, Rock JP, Rosenblum ML: Spinal epidural abscess: evaluation of factors influencing outcome. Neurosurgery 39:958-964, 1996

27. Kim SD, Melikian R, Ju KL, Zurakowski D, Wood KB, Bono $\mathrm{CM}$, et al: Independent predictors of failure of nonoperative management of spinal epidural abscesses. Spine J 30:0160601609, 2013

28. Krödel A, Krüger A, Lohscheidt K, Pfahler M, Refior HJ: Anterior debridement, fusion, and extrafocal stabilization in the treatment of osteomyelitis of the spine. J Spinal Disord 12: 17-26, 1999

29. Küker W, Mull M, Mayfrank L, Töpper R, Thron A: Epidural spinal infection. Variability of clinical and magnetic resonance imaging findings. Spine (Phila Pa 1976) 22:544-551, 1997

30. Lau D, Maa J, Mummaneni PV, Chou D: Holospinal epidural abscess. J Clin Neurosci 21:517-520, 2014

31. Lehman RA Jr, Lenke LG: Extensive epidural abscess treated with a thoracic laminoplasty. Spine J 11:798-799, 2011

32. Leonard J, Kaufman B: Treatment of a holocord epidural abscess. Case illustration. J Neurosurg 94 (1 Suppl):179, 2001 
33. Lin WS, Kao HW, Cheng CA: Panspinal epidural abscess concomitant with meningitis. Am J Emerg Med 31:1155. e5-1155.e6, 2013

34. O'Brien C, Lenehan B, Street J: Non-operative management of an extensive anteriorly located epidural abscess. J Clin Neurosci 18:1401-1402, 2011

35. Ong CW, Hsu LY, Tambyah PA: Corticosteroids for bacterial meningitis. N Engl J Med 358:1399-1401, 2008 (Letter)

36. Parkinson JF, Sekhon LH: Spinal epidural abscess: appearance on magnetic resonance imaging as a guide to surgical management. Report of five cases. Neurosurg Focus 17(6):E12, 2004

37. Patel AR, Alton TB, Bransford RJ, Lee MJ, Bellabarba CB, Chapman JR: Spinal epidural abscesses: risk factors, medical versus surgical management, a retrospective review of 128 cases. Spine J 14:326-330, 2014

38. Pereira CE, Lynch JC: Spinal epidural abscess: an analysis of 24 cases. Surg Neurol 63 (Suppl 1):S26-S29, 2005

39. Pfister HW, von Rosen F, Yousry T: MRI detection of epidural spinal abscesses at noncontiguous sites. J Neurol 243:315317, 1996

40. Pola E, Logroscino CA, Gentiempo M, Colangelo D, Mazzotta V, Di Meco E, et al: Medical and surgical treatment of pyogenic spondylodiscitis. Eur Rev Med Pharmacol Sci 16 (Suppl 2):35-49, 2012

41. Reihsaus E, Waldbaur H, Seeling W: Spinal epidural abscess: a meta-analysis of 915 patients. Neurosurg Rev 23:175-205, 2000

42. Richardson J, Groen GJ: Applied epidural anatomy. CEACCP 5:98-100, 2005

43. Russell NA, Vaughan R, Morley TP: Spinal epidural infection. Can J Neurol Sci 6:325-328, 1979

44. Safran O, Rand N, Kaplan L, Sagiv S, Floman Y: Sequential or simultaneous, same-day anterior decompression and posterior stabilization in the management of vertebral osteomyelitis of the lumbar spine. Spine (Phila Pa 1976) 23:1885-1890, 1998

45. Savage K, Holtom PD, Zalavras CG: Spinal epidural abscess: early clinical outcome in patients treated medically. Clin Orthop Relat Res 439:56-60, 2005

46. Shah NH, Roos KL: Spinal epidural abscess and paralytic mechanisms. Curr Opin Neurol 26:314-317, 2013

47. Shiu SI, Lee BJ, Chen HC, Lin YH, Wang CY: Holospinal epidural abscess complicated with bilateral psoas muscle abscess. Spine J 14:1072-1073, 2014
48. Shoakazemi A, Amit A, Nooralam N, Abouharb A, Gormley M, McKinstry S: Panspinal epidural and psoas abscess with secondary cervical disc space infection. Ulster Med J 82: 23-25, 2013

49. Simpson RK Jr, Azordegan PA, Sirbasku DM, Weathers SW, Lidsky MD, Baskin DS: Rapid onset of quadriplegia from a panspinal epidural abscess. Spine (Phila Pa 1976) 16:10021005, 1991

50. Smith C, Kavar B: Extensive spinal epidural abscess as a complication of Crohn's disease. J Clin Neurosci 17:144-146, 2010

51. Tahir MZ, Hassan RU, Enam SA: Management of an extensive spinal epidural abscess from C-1 to the sacrum. Case report. J Neurosurg Spine 13:780-783, 2010

52. Taylor AR, Byrnes DP: Foramen magnum and high cervical cord compression. Brain 97:473-480, 1974

53. Van Bergen J, Plazier M, Baets J, Simons PJ: An extensive spinal epidural abscess successfully treated conservatively. J Neurol Neurosurg Psychiatry 80:351-353, 2009

54. Vaught KA: Spinal surgery: an unusual case of spinal epidural abscess. Mo Med 106:297-300, 2009

55. Velazquez A, DeRyke CA, Goering R, Hoover V, Wallace MR: Daptomycin non-susceptible Staphylococcus aureus at a US medical centre. Clin Microbiol Infect 19:1169-1172, 2013

56. Wang Z, Lenehan B, Itshayek E, Boyd M, Dvorak M, Fisher C, et al: Primary pyogenic infection of the spine in intravenous drug users: a prospective observational study. Spine (Phila Pa 1976) 37:685-692, 2012

57. Wells RD, Bebarta VS: Primary iliopsoas abscess caused by community-acquired methicillin-resistant Staphylococcus aureus. Am J Emerg Med 24:897-898, 2006

\section{Manuscript submitted April 15, 2014.}

Accepted May 28, 2014.

Please include this information when citing this paper: DOI: 10.3171/2014.5.FOCUS14136.

Address correspondence to: Gabriel A. Smith, M.D., Department of Neurosurgery, University Hospitals, Case Western Reserve University, 11100 Euclid Ave., 5th Floor, Hanna House, Cleveland, OH 44106. email: gabriel.smith@ uhhospitals.org. 